\title{
Páramo is the world's fastest evolving and coolest biodiversity hotspot
}

\author{
Santiago Madriñán ${ }^{1 *}$, Andrés J. Cortés ${ }^{1,2}$ and James E. Richardson ${ }^{1,3}$ \\ ' Laboratorio de Botánica y Sistemática, Departamento de Ciencias Biológicas, Universidad de los Andes, Bogotá, DC, Colombia \\ ${ }^{2}$ Evolutionary Biology Centre, Department of Plant Ecology and Genetics, Uppsala University, Uppsala, Sweden \\ ${ }^{3}$ Tropical Diversity Section, Royal Botanic Garden Edinburgh, Edinburgh, UK
}

Edited by:

Federico Luebert, Freie Universität Berlin, Germany

Reviewed by:

Christopher W. Dick, University of

Michigan, USA

Petr Sklenar, Charles University,

Czech Republic

\section{*Correspondence:}

Santiago Madriñán, Laboratorio de

Botánica y Sistemática, Universidad de los Andes, Apartado Aéreo 4976, Bogotá, DC 111711, Colombia

e-mail:samadrin@uniandes.edu.co
Understanding the processes that cause speciation is a key aim of evolutionary biology. Lineages or biomes that exhibit recent and rapid diversification are ideal model systems for determining these processes. Species rich biomes reported to be of relatively recent origin, i.e., since the beginning of the Miocene, include Mediterranean ecosystems such as the California Floristic Province, oceanic islands such as the Hawaiian archipelago and the Neotropical high elevation ecosystem of the Páramos. Páramos constitute grasslands above the forest tree-line (at elevations of c. 2800-4700 m) with high species endemism. Organisms that occupy this ecosystem are a likely product of unique adaptations to an extreme environment that evolved during the last three to five million years when the Andes reached an altitude that was capable of sustaining this type of vegetation. We compared net diversification rates of lineages in fast evolving biomes using 73 dated molecular phylogenies. Based on our sample, we demonstrate that average net diversification rates of Páramo plant lineages are faster than those of other reportedly fast evolving hotspots and that the faster evolving lineages are more likely to be found in Páramos than the other hotspots. Páramos therefore represent the ideal model system for studying diversification processes. Most of the speciation events that we observed in the Páramos (144 out of 177) occurred during the Pleistocene possibly due to the effects of species range contraction and expansion that may have resulted from the well-documented climatic changes during that period. Understanding these effects will assist with efforts to determine how future climatic changes will impact plant populations.

Keywords: biodiversity hotspots, biogeography, evolutionary radiation, dated molecular phylogenies, net diversification rates, plant evolution, Páramos

\begin{abstract}
"No zone of alpine vegetation in the temperate or cold parts of the globe can well be compared with that of the Páramos in the tropical Andes." "Nowhere, perhaps, can be found collected together, in so small a space, productions so beautiful, and so remarkable in regard to the geography of plants."

Alexander von Humboldt Aspects of Nature \& Personal narrative
\end{abstract}

\section{INTRODUCTION}

The processes by which lineages diverge into new species are still poorly understood but are more likely to be determined in lineages that have recently speciated or are undergoing incipient speciation (Rieseberg and Willis, 2007). Biomes that have numerous examples of lineages that have speciated recently and rapidly would therefore be ideal places to study evolutionary phenomena. Studies that utilize dated phylogenies have reported high net diversification rates in a variety of biomes many of which are also designated biodiversity hotspots (Myers et al., 2000), for example Succulent Karoo (Klak et al., 2004) or the Mediterranean Basin (Valente et al., 2010). These radiations may have been caused by a variety of factors including recent geological activity (e.g., Hawaii that is part of the Polynesia-Micronesia hotspot) (Baldwin and Sanderson, 1998; Price and Wagner, 2004), or recent climatic change (e.g., Succulent Karoo).

In the Neotropics, lowland forests such as the Amazon have received a substantial amount of attention as species rich ecosystems (Hoorn et al., 2010). However, the high elevation tropical Andean Páramo ecosystem is not as widely recognized as a center of plant diversity. With 3431 species of vascular plants (Luteyn, 1999), Páramos may be considered a hotspot within a hotspot, as it is located within that of the Tropical Andes (Myers et al., 2000). Páramos are found at a number of isolated mountaintops at altitudes of between 2800 and $4700 \mathrm{~m}$ above sea level forming an archipelago-like distribution between latitudes of $11^{\circ} \mathrm{N}$ and $8^{\circ} \mathrm{S}$ covering approximately $35,000 \mathrm{~km}^{2}$ (Figure 1). The physical characteristics of the area occupied by this ecosystem include aseasonal conditions with high daytime and low nighttime temperatures, continuously high solar energy input, and high ultraviolet radiation (Luteyn, 1999). The great majority of the plant species found in the Páramos are endemic to this ecosystem, with close relatives in lowland-tropical or northand south-temperate regions (van der Hammen and Cleef, 1986) (Figure 2). These ecosystems may be considered the "water towers" of South America as they provide large reservoirs that serve 


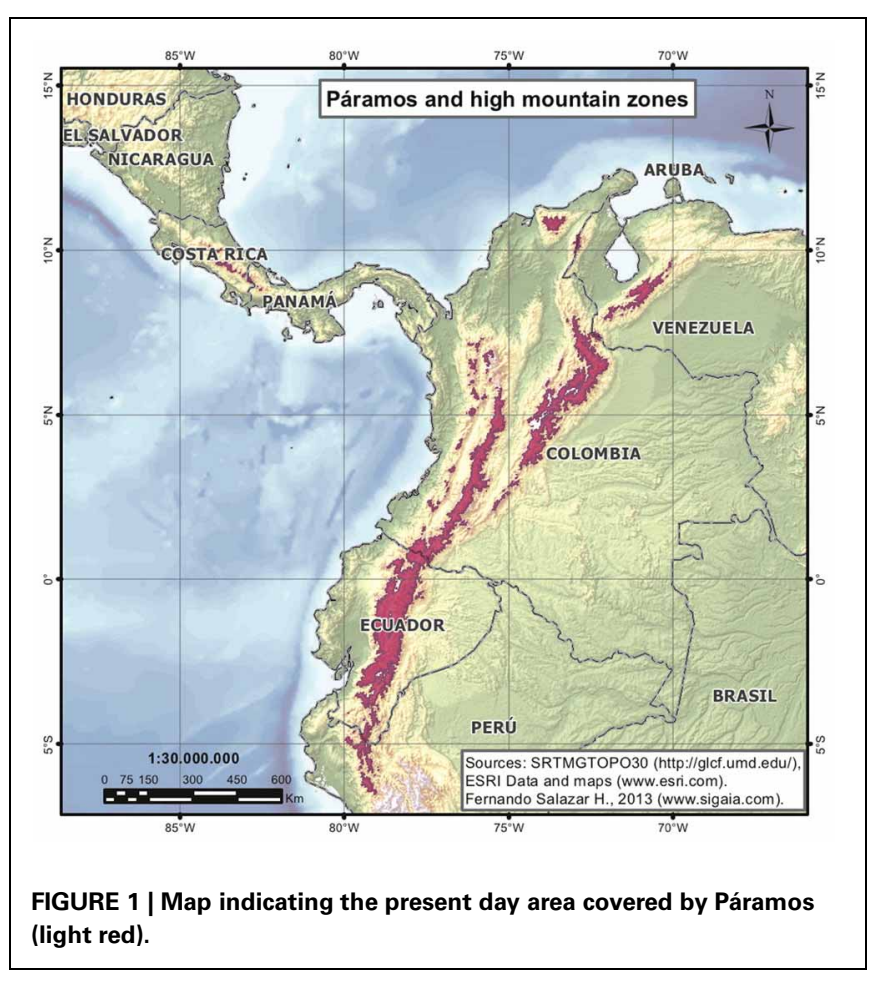

many of the major Andean cities. Páramos are under threat from mining activities (gold, coal, and lime) and climate change.

Evolution of the Páramo ecosystem was entirely dependent on the Andean orogeny as the ecosystem could only have developed once the Andes had reached a sufficient height. It has been estimated that the northern Andes reached $40 \%$ of its modern elevation from the mid-Miocene/early Pliocene and that they rose to current heights through rapid final uplift only by around 2.7 million years (Ma) ago (Gregory-Wodzicki, 2000; Mora et al., 2010). The northern Andes reached the altitude of the modern tree line that marks the lower limit of Páramo vegetation near the end of the Pliocene at $2.588 \mathrm{Ma}$ ago (van der Hammen and Hooghiemstra, 2000). These are therefore the approximate dates by which conditions suitable for development of the Páramo ecosystem had established. By the late Pliocene/Early Pleistocene a proto-páramo vegetation occupied large areas between 2000 and $3000 \mathrm{~m}$ (van der Hammen, 1974; Hooghiemstra and van der Hammen, 2004). This vegetation type was characterized by pollen of modern Páramo elements such as Poaceae, Valeriana, Plantago, Aragoa, Ranunculaceae, Caryophyllaceae, Geranium, Gunnera, Gentianella and Lysipomia. However, pollen is not sufficiently diagnostic at species level to determine when speciation in these groups occurred.

Pleistocene changes in the distribution of this vegetation type and thus the species that occupy it are evident in the fossil record (van der Hammen, 1974). Individual plant species may have been forced to migrate vertically and the composition and distributions of plant communities would thus have been highly dynamic, with vegetation belts alternately contracting and expanding. During glacial maxima the area of Páramos was considerably larger than in inter-glacial periods as Páramo islands occupied lower elevations and thus merged when temperatures were lower (Hooghiemstra et al., 2006). These changes in distribution, which are largely mediated by temperature fluctuation, are more likely to be greater in a dissected montane landscape where there are rapid changes in elevation across small distances. These abiotic conditions would seem to be an ideal scenario for rapid allopatric speciation and perhaps also permit more rapid occupation of newly available and novel niche space. Indeed the Páramos have been characterized by several examples of rapid diversification events, demonstrated using dated molecular phylogenies (Särkinen et al., 2012), in genera such as Gentianella (von Hagen and Kadereit, 2001), Valeriana (Bell and Donoghue, 2005), Lupinus (Hughes and Eastwood, 2006) and Hypericum (Nürk et al., 2013). An increasing amount of sequence data and calibration points are becoming available permitting the production of dated phylogenies of plant groups from multiple lineages, allowing a comparison of net diversification rates amongst hotspots. Here we demonstrate that Páramos are undergoing an explosive phase of diversification that is both more rapid and more recent than in any other hotspot.

\section{MATERIALS AND METHODS DATA AND SAMPLING FOR PÁRAMO LINEAGES}

Sequence data generated in the laboratory of the first author or downloaded from GenBank were assembled and aligned for eight Páramo genera. Five additional phylogenies, taken from the literature, of genera containing Páramo clades were also included in this study (see Supporting Information). Dated phylogenies were estimated using the software package BEAST 1.4.8 (Drummond and Rambaut, 2007) using primary or secondary fossil calibrations or in one instance a geological calibration (see below and Table S1). In instances where these approaches to calibration were not possible we chose not to apply rates from other studies of taxa with a similar generation time (generation time has been shown to have an effect on rates) (Richardson et al., 2001; Smith and Donoghue, 2008) because of the expected elevated mutation rate, resulting from high U.V. light, in high altitude tropical ecosystems. Age estimates of crown nodes with confidence intervals were then utilized to estimate net diversification rates. Species and GenBank numbers for sequences used in the study are given in Appendix S1.

\section{AGES OF CLADES FROM OTHER HOTSPOTS}

We compiled data from published dated phylogenetic studies from Páramo and other hotspots. These used a number of approaches to date phylogenies and we preferred those results that used internal fossil primary or secondary calibrations although in their absence those that used geological calibrations (i.e., oceanic island emergence) were considered acceptable. We also reported results of studies in hotspots other than Páramo that used borrowed rates from lineages with similar generation times but did not include these in our calculations for Páramo studies because, as mentioned above, we consider species that occupy that ecosystem to have an elevated substitution rate as a result of the intense U.V. light that is found in tropical highlands. This elevated rate might skew the result in favor of older age estimates of Páramo lineages. Lineages such as Halenia (Gentianaceae) 


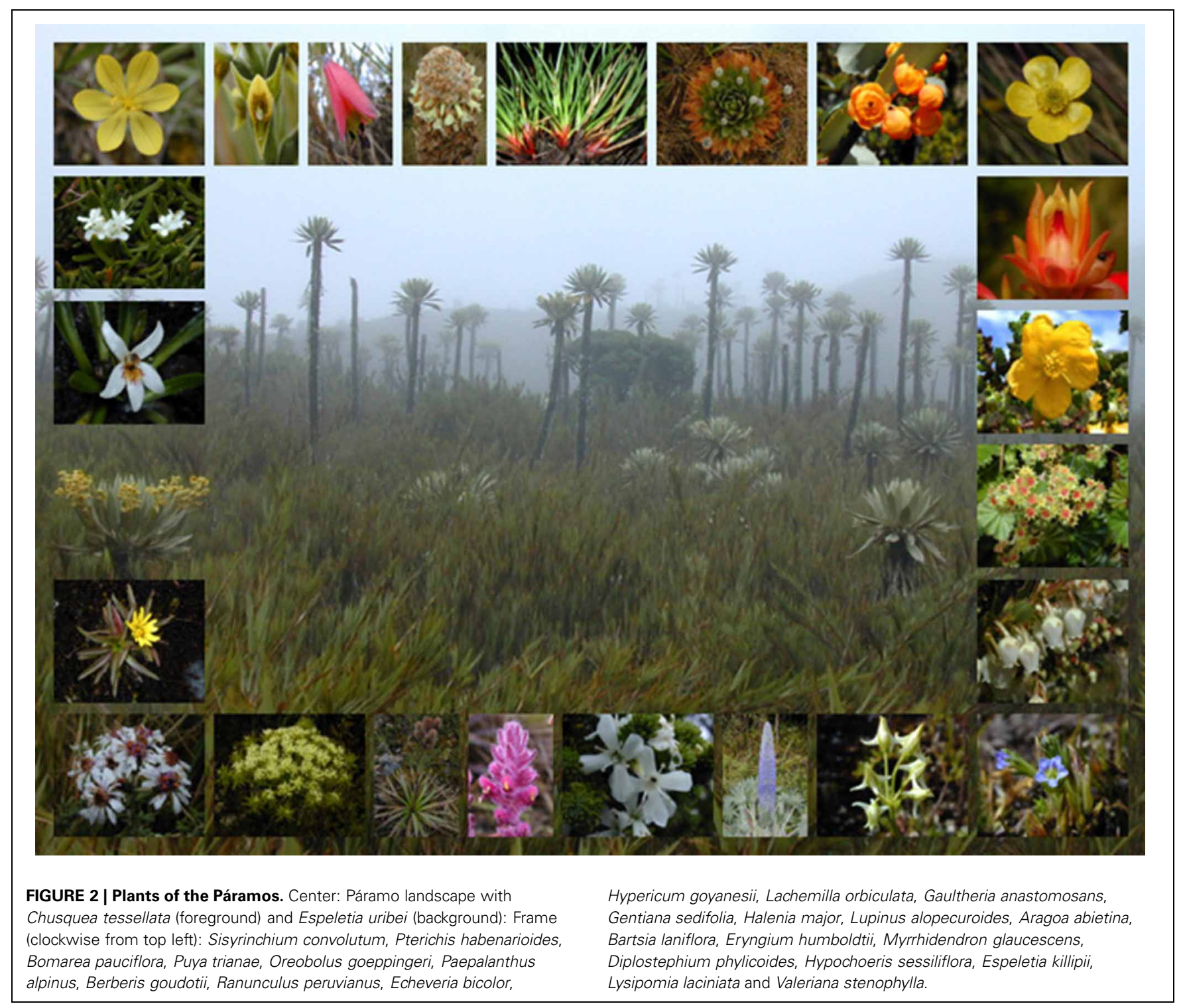

should therefore actually have a higher net diversification rate than we would estimate by applying the fastest reported rate for herbaceous annuals.

If alternative options were available the date chosen was the one that was calibrated using fossils rather than geological events due to problems with the latter approach highlighted by Renner (2005). As different dates result from different analytical approaches we favored dates calculated by Bayesian methods followed by penalized likelihood and then NPRS (the latter has been shown to over-estimate ages) (Lavin et al., 2005). Favoring of Bayesian age estimates also permitted a more direct comparison with results of our analyses of Páramo lineages all of which used that approach.

Species numbers of Heliophila in each hotspot were taken from Marais (1970). The age reported for Kokia is that of the stem node and therefore an underestimate of the rate presented. Mediterranean studies of Geranium and Erodium are possible underestimates as only endemic species were included but those studies also included species outside the Mediterranean basin that we were unable to exclude because of a lack of distribution information. In some cases it was difficult to assess actual numbers of species of lineages in other biomes, e.g., Fabaceae lineages in the Cape Floristic Region likely have species that occur outside of that region. In some of our examples we included all species in a genus in our estimates even when it is likely that not all species are found within that biome which means we are overestimating net diversification rates in those lineages.

\section{DETERMINATION OF AGES OF PÁRAMO CLADES}

A Bayesian dating method with a relaxed molecular clock was implemented using the program BEAST 1.4.8 (Drummond and Rambaut, 2007) to estimate divergence times. An XML (eXtensible Mark-up Language) input file was generated in the Bayesian Evolutionary Analysis Utility software (BEAUti) version v.1.4.8 (Drummond and Rambaut, 2007) (XML files for each analysis are available upon request to the corresponding author). The 


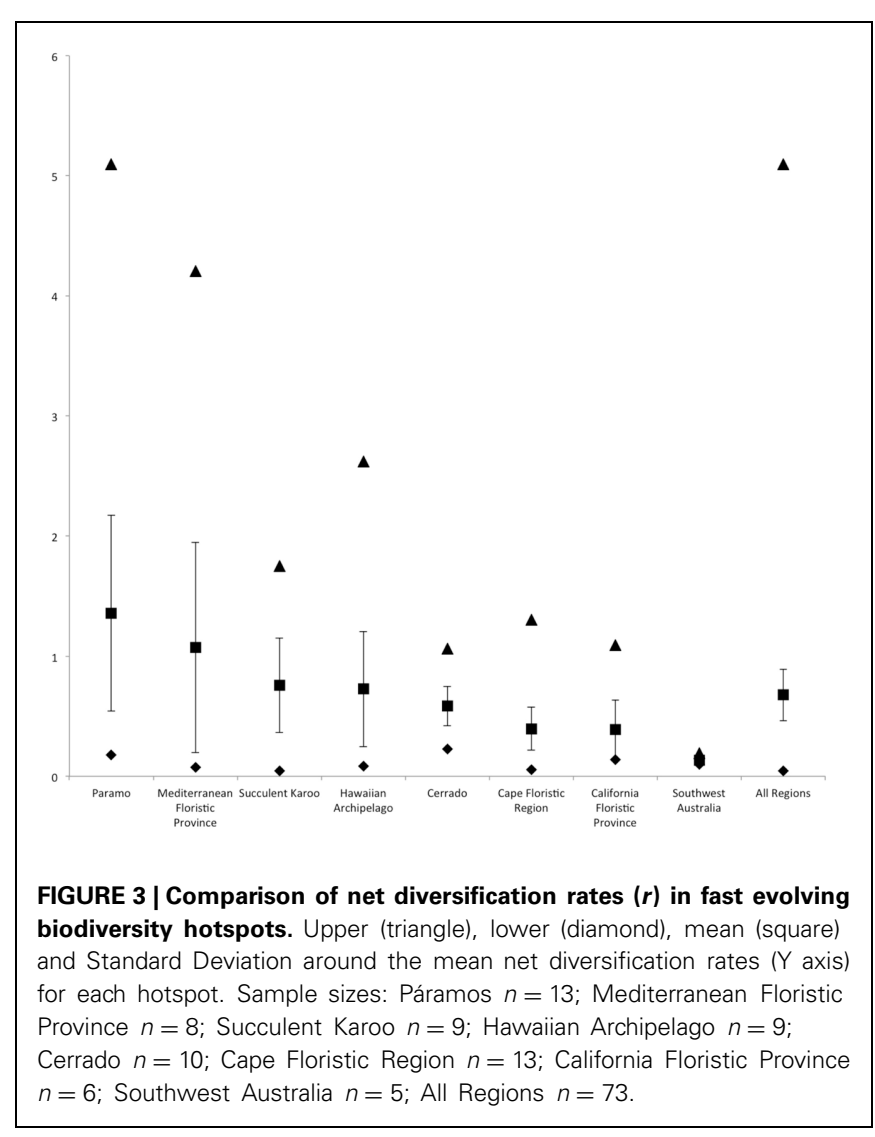

best performing evolutionary model was identified under two different model selection criteria, the hierarchical likelihood ratio test (hLRT) and the Akaike information criterion as implemented in MrModelTest (Nylander, 2004). Both selection criteria indicated that for each data set a General Time Reversible (GTR) with site heterogeneity being gamma distributed and with invariant sites model was optimal. An uncorrelated lognormal relaxed clock model was chosen based on the assumption of the absence of a molecular clock. To specify informative priors for all the parameters in the model, the Yule tree prior was used that was recommended as being appropriate for species-level phylogenies (Ho, 2007). As also recommended by Ho (2007), a log normal prior distribution was applied to fossil based calibrations and a normal distribution was used for secondary calibrations. The XML file was run in BEAST 1.4.8 (Drummond and Rambaut, 2007). Two runs were performed for each analysis. The MCMC chain length was set to $10,000,000$, to screen every 10,000 and sample every 1000 trees. The resulting log file was imported into Tracer to check whether ESS values were adequate for each parameter. If they were not additional runs of 10,000,000 generations were performed until adequate ESS values were achieved. LogCombiner (Drummond and Rambaut, 2007) was used to combine tree files in cases where multiple runs were necessary. TreeAnnotator (Drummond and Rambaut, 2007) was used to produce the maximum clade credibility (MCC) tree that has the maximum sum of posterior probabilities on its internal nodes and summarizes the node height statistics in the posterior sample.
MCC files were visualized using FigTree version 1.2.3 (Rambaut, 2009) and median and 95\% highest posterior density (HPD) ages are reported in Table S1. We also calculated the number of species that, based on their median ages, diverged from their MRCA during the Pleistocene, i.e., within the last 2.58 million years, for each Páramo lineage.

\section{CALCULATION OF NET DIVERSIFICATION RATES}

There are a number of diversification rate measures but we report that of the simple estimator of Kendall (1949) and Moran (1951) where $\left.r=\ln (N)-\ln \left(N_{0}\right)\right] / T$ (where $N=$ standing diversity, $N_{0}$ $=$ initial diversity, here taken as $=1$, and $T=$ inferred clade age). This estimate, a pure-birth model of diversification with a constant rate and no extinction, is the same as that of Magallón and Sanderson (2001).

\section{STATISTICAL ANALYSES}

Average net diversification rates of all lineages within hotspots were calculated and a $95 \%$ bootstrap interval, using 1000 iterations, around each mean diversification rate was determined for each hotspot. Number of species, crown node age, mean diversification rate and number of Pleistocene speciation events for each Páramo lineage in the study are indicated in Table $\mathbf{1}$ (chronograms for each study are indicated in Figures S1A-H; Table S1 includes data on taxa from other hotspots).

Re-sampling without replacement was carried out 1000 times in order to estimate the probability that the fastest evolving lineage comes from a particular region. In each re-sampling step, five lineages per hotspot were randomly chosen across the eight hotspots, and the region where the fastest evolving lineage came from was identified from the 40 total randomly chosen lineages. The numbers of consecutive fastest evolving lineages that belong to the same region were also recorded. Two summary statistics per hotspot were calculated based on the 1000 sampling processes: the proportion of cases where the fastest evolving lineage came from a particular region and the maximum number of consecutive fastest evolving lineages that belong to the same region. Mean and confidence intervals for these two summary statistics were calculated running 1000 independent iterations of 1000 samples each. The summary statistics, their means and their confidence intervals are presented in Table S2.

\section{RESULTS}

Páramo lineages have higher net diversification rates than the fastest known lineages in other hotspots and have the fastest mean diversification rate of all hotspots (Figure 3; Table 2). The average diversification rate of the Páramo lineages sampled (Tables 1,2) is 1.36 speciation events per million years (Myr-1; $n=13$; we report values for a pure-birth model of diversification, one with a constant rate and no extinction $r$ (Kendall, 1949; Moran, 1951; Magallón and Sanderson, 2001) (see Calculation of net diversification rates in methods above); rates factoring in extinction are reported in Table S1) compared with 1.07 Myr1 in the Mediterranean Basin $(n=8), 0.76$ Myr-1 in Succulent Karoo $(n=9), 0.73$ Myr-1 in Hawaii $(n=9), 0.58$ Myr-1 in Cerrado $(n=10), 0.40$ Myr- 1 in the Cape Floristic Region $(n=$ 13), 0.39 Myr-1 in the California Floristic Province $(n=6)$ 
Table 1 | Net diversification rates of Páramo plant lineages.

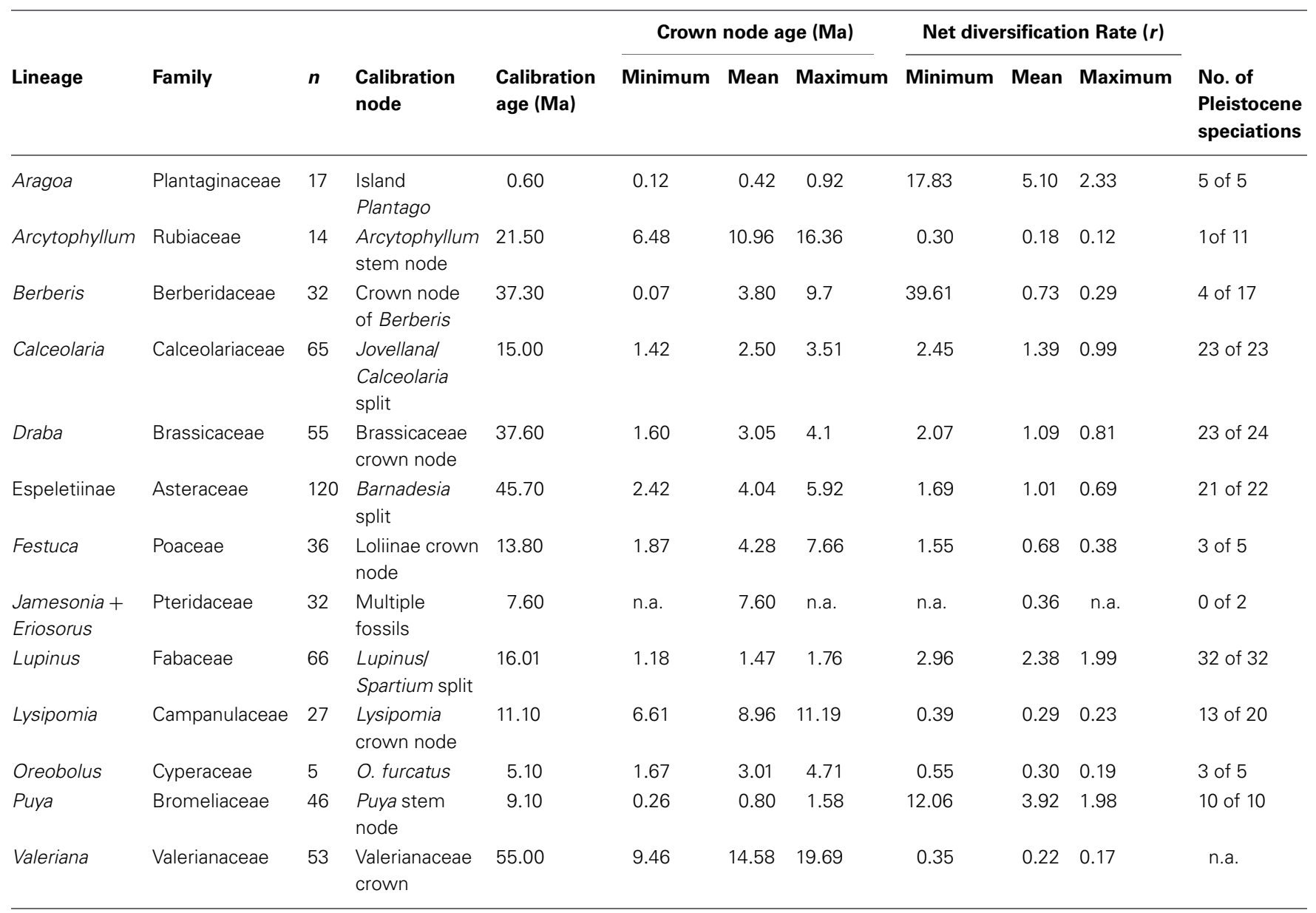

n, number of species within lineage; n.a., not available; Ma, million years ago.

and 0.14 Myr-1 in Southwest Australia $(n=5)$. There are isolated lineages in some hotspots that have high rates such as in Dianthus (Valente et al., 2010) and core Ruschioideae (Klak et al., 2004). However, the average rate is significantly higher in Páramos than it is for a random sample of 13 from within our dataset of all hotspots. We also show that the fastest evolving lineage has a greater probability of being from the Páramos (0.51) than from any other hotspot $(0.40$ for the Mediterranean and 0.02 for Succulent Karoo; Table S2). The average number of fastest lineages that belong to the same region is also greatest in Páramos. In addition to the rapid net diversification rates, Páramos have a very high species density in comparison to other hotspots with 3431 species, nearly all of which occur nowhere else. Table 2 indicates the values for other hotspots and also that although the Cape Floristic Region has more species per kilometer squared than Páramos, the average rate per area in Páramos is greater than the Cape Floristic Region and all other hotspots studied.

\section{DISCUSSION}

We demonstrate that Páramos not only have had a rapid diversification rate but those radiations have also been more recent than in other hotspots. In addition these diversifications have occurred more or less over the same period of time in multiple unrelated lineages in contrast to, for example, the single rapid diversification of cichlid fishes that occurred in a restricted area in East African lakes (Kornfield and Smith, 2000). Additional recent studies of evolutionary histories are also consistent with the rapid diversification of other Páramo lineages (Vargas and Madriñán, 2012; Nürk et al., 2013). Because Páramo lineages are in an early explosive phase of diversification we expect current species composition to be the result of on-going speciation processes with extinction having a minimal effect. Possible causes of diversification in Páramos include allopatric speciation resulting from distribution changes caused by climatic cycles during the Pleistocene or, adaptation to numerous new microclimates and substrates resulting from geological activity associated with Andean uplift. We acknowledge that diversification of some lineages may have occurred prior to the Plio-Pleistocene. However, our chronograms indicate that, based on median ages, 144 of the 176 Páramo species in our study split from their MRCA during the Pleistocene (Table 1) that is consistent with them having arisen as a result of inter-glacial range contractions in that epoch. We assume that the addition of more species to our sample will increase this figure. Although allopatric speciation could be the primary cause of isolation, the high levels of ultraviolet light are likely to induce 
Table 2 | Biodiversity Hotspots species richness and mean net diversification rates.

\begin{tabular}{|c|c|c|c|c|c|}
\hline Region & $\begin{array}{l}\text { Area } \\
\left(\mathbf{k m}^{2}\right)\end{array}$ & $\begin{array}{l}\text { No. of } \\
\text { species } \\
\text { (endemics) }\end{array}$ & $\begin{array}{l}\text { No. of } \\
\text { species } / \mathbf{k m}^{2}\end{array}$ & $\begin{array}{l}\text { Mean Net } \\
\text { Diversification } \\
\text { rate }\end{array}$ & $\begin{array}{l}\text { Speciation events per } \\
\text { million years per } \\
\mathbf{k m}^{2}\end{array}$ \\
\hline California Floristic Province & 293,804 & $8000(2124)$ & 0.027 & 0.39 & $1.32 \times 10^{-6}$ \\
\hline Cape Floristic Region & 78,555 & $9000(6210)$ & 0.196 & 0.40 & $5.05 \times 10^{-6}$ \\
\hline Cerrado & $2,031,990$ & $12,669(4215)$ & 0.060 & 0.58 & $0.29 \times 10^{-6}$ \\
\hline Hawaiian Archipelago & 28,311 & 1004 (c. 900) & 0.035 & 0.73 & $25.68 \times 10^{-6}$ \\
\hline Mediterranean Floristic Province & $2,085,292$ & $22,500(11,700)$ & 0.010 & 1.07 & $0.52 \times 10^{-6}$ \\
\hline Páramos & 35,000 & $3431\left(^{*}\right)$ & 0.098 & 1.36 & $38.80 \times 10^{-6}$ \\
\hline Southwest Australia & 356,717 & $5500(2948)$ & 0.015 & 0.14 & $0.38 \times 10^{-6}$ \\
\hline Succulent Karoo & 102,691 & $6350(2439)$ & 0.062 & 0.76 & $7.38 \times 10^{-6}$ \\
\hline
\end{tabular}

${ }^{*}$ Precise number of endemic species unknown, but close to $100 \%$.

a rapid mutation rate (Davies et al., 2004; Willis et al., 2009), and therefore hasten morphological differentiation and perhaps reproductive isolation with these mutations being more likely to become fixed in small fragmented populations. It is also possible that ecological opportunity and physiographic heterogeneity were the primary factors driving rapid diversification, e.g., Andean Lupinus (Hughes and Eastwood, 2006). The actual processes of speciation remain unclear, however, what is evident from this study is that it occurred more rapidly in Páramos than in any other hotspot on earth and confirms Hughes and Eastwood's (2006) prediction that the species-richness of the flora is the result of a set of rapid plant radiations.

Species that occupy steep altitudinal gradients are likely to undergo altitudinal range shifts with changes in temperature and are therefore ideal organisms to model the effects of historical and potential future changes. High altitude restricted species are also the most threatened due to the limited areas into which they can migrate under conditions of increasing temperatures such as those we are currently experiencing. The relatively small areas of Páramo vegetation make them logistically easier to study. For example, fragmented areas of Páramos around Bogotá that are as little as $30 \mathrm{~km}$ apart and would likely (based on palaeobotanical evidence from the Sabana de Bogotá (van der Hammen, 1973, 1974; van der Hammen and Cleef, 1986) have been connected during the last glacial maximum may be studied to look for signatures of fragmentation processes that occurred within the last 10,000 years and in previous inter-glacial periods.

When faced with changing climatic conditions, such as temperature increases, populations respond either by adapting, going extinct or migrating (Fordham et al., 2012). The contraction and expansion of populations that is very evident in Páramos according to palaeoecological data (van der Hammen, 1974; Hooghiemstra and van der Hammen, 2004), and that could have

\section{REFERENCES}

Baldwin, B. G., and Sanderson, M. J. (1998). Age and rate of diversification of the Hawaiian silversword alliance (Compositae). Proc. Natl. Acad. Sci. U.S.A. 95, 9402-9406. doi: 10.1073/pnas.95.16.9402

Bell, C. D., and Donoghue, M. J. (2005). Phylogeny and biogeography of

resulted in the high number of Pleistocene speciation events reported here, is indicative of an inability to adapt to changing conditions, as demonstrated in other montane systems (Colwell et al., 2008; Kelly and Goulden, 2008; Lenoir et al., 2008). This inability to adapt over periods of thousands of years reinforces the dangers that plant populations face in these environments when challenged by changes that might occur over shorter time scales of decades or centuries. Research into Páramo plants will help us to understand past and future evolutionary processes and provide the information necessary to help to conserve this and other ecosystems in the face of the continuing pressures exerted by anthropogenic climatic alterations.

\section{ACKNOWLEDGMENTS}

Thanks to Tony Verboom, Klaus Mummenhoff, Peter Goldblatt, Freek Bakker, Peter Linder, Jenny Archibald, Chloe Galley and Felix Forest for supplying accurate dates and/or species numbers for Cape/Succulent Karoo and Mike Crisp for supplying accurate dates and species numbers for Southwest Australian lineages. Juan José Aldasoro is thanked for additional information on Geraniaceae node ages and thanks to Isabel Sanmartín for help with other Mediterranean studies. Diego Riaño is thanked for help with BEAST analyses. Thanks to Michael Donoghue, Colin Hughes, Kyle Dexter and the Royal Botanic Garden Edinburgh Journal Club for comments on the manuscript. Bhaskar Adhikari (RBGE) and Maria Pinilla (Universidad de Los Andes) are thanked for use of unpublished data. We are gratefull to Fernando Salazar for the production of the map of the Páramos.

\section{SUPPLEMENTARY MATERIAL}

The Supplementary Material for this article can be found online at: http://www.frontiersin.org/journal/10.3389/fgene.2013.00192/ abstract

attrition in the wet tropics. Science 322, 258-261. doi: 10.1126/science. 1162547

Davies, T. J., Savolainen, V., Chase, M. W., Moat, J., and Barraclough, T. G. (2004). Environmental energy and evolutionary rates in flowering plants. Proc. $R$. Soc. Lond. B Biol. Sci. 271,
2195-2200. doi: 10.1098/rspb. 2004.2849

Drummond, A. J., and Rambaut, A. (2007). BEAST: bayesian evolutionary analysis by sampling trees. $B M C$ Evol. Biol. 7:214. doi: 10.1186/14712148-7-214

Fordham, D. A., Resit, H. Akaya, A. K. C., Araújo, M. B., Elith, J., Keith, 
D. A., et al. (2012). Plant extinction risk under climate change: are forecast range shifts alone a good indicator of species vulnerability to global warming? Glob. Chang. Biol. 18, 1357-1371. doi: 10.1111/j.13652486.2011.02614.x

Gregory-Wodzicki, K. M. (2000). Uplift history of the Central and Northern Andes: a review. Geol. Soc. Am. Bull. 112, 1091-1105. doi: 10.1130/0016-7606(2000)112< 1091:UHOTCA>2.0.CO;2

Ho, S. Y. M. (2007). Calibrating molecular estimates of substitution rates and divergence times in birds. J. Avian. Biol. 38, 409-414. doi: 10.1111/j.2007.0908-8857.04168.x

Hooghiemstra, H., and van der Hammen, T. (2004). Quaternary Ice-Age dynamics in the Colombian Andes: developing an understanding of our legacy. Philos. Trans. R. Soc. Lond. B Biol. Sci. 359, 173-181. doi: $10.1098 /$ rstb.2003.1420

Hooghiemstra, H., Wijninga, V., and Cleef, A. (2006). The palaeobotanical record of Colombia: implications for biogeography and biodiversity. Ann. Mo. Bot. Gard. 93, 297-325. doi: 10.3417/0026-6493 (2006)93 [297:TPROCI]2.0.CO;2

Hoorn, C., Wesselingh, F. P., ter Steege, H., Bermudez, M. A., Mora, A., Sevink, J., et al. (2010). Amazonia through time: andean uplift, climate change, landscape evolution, and biodiversity. Science 330, 927-931. doi: 10.1126/science.1194585

Hughes, C., and Eastwood, R. (2006). Island radiation on a continental scale: exceptional rates of plant diversification after uplift of the Andes. Proc. Natl. Acad. Sci. U.S.A. 103, 10334-10339. doi: 10.1073/ pnas.0601928103

Kelly, A., and Goulden, M. (2008). Rapid shifts in plant distribution with recent climate change. Proc. Natl. Acad. Sci. U.S.A. 105, 11823-11826. doi: 10.1073/pnas. 0802891105

Kendall, D. G. (1949). Stochastic processes and population growth. J. R. Stat. Soc. B Stat. Methodol. 11, 230-264.

Klak, C., Reeves, G., and Hedderson, T. (2004). Unmatched tempo of evolution in southern African semi-desert ice plants. Nature 427, 63-65. doi: 10.1038 /nature 02243

Kornfield, I., and Smith, P. F. (2000). African Cichlid fishes: model systems for evolutionary biology. Annu. Rev. Ecol. Evol. Syst. 31, 163-196. doi: 10.1146/annurev. ecolsys.31.1.163

Lavin, M., Herendeen, P., and Wojciechowski, M. F. (2005). Evolutionary rates analysis of Leguminosae implicates a rapid diversification of lineages during the Tertiary. Syst. Biol. 54, 530-549. doi: 10.1080/10635150590947131

Lenoir, J., Gégout, J. C., Marquet, P. A., de Ruffray, P., and Brisse, $\mathrm{H}$. (2008). A significant upward shift in plant species optimum elevation during the 20th century. Science 320, 1768-1771. doi: 10.1126/science. 1156831

Luteyn, J. L. (1999). Páramos: a Checklist of Plant Diversity, Geographic Distribution and Botanical Literature. New York, NY: The New York Botanical Garden Press.

Magallón, S., and Sanderson, M. J. (2001). Absolute diversification rates in angiosperm clades. Evolution 55, 1762-1780. doi: 10.1554/0014-3820(2001)055[1762: ADRIAC]2.0.CO;2

Marais, W. (1970). "Heliophila," in Flora of Southern Africa, Vol. 13, eds L. E. Codd, B. de Winter, D. J. B. Killick, and H. B. Rycroft (Pretoria: Botanical Research Institute), 17-77.

Mora, A., Baby, P., Roddaz, M., Parra, M., Brusset, S., Hermoza, W., et al. (2010). "Tectonic history of the Andes and sub-Andean zones: implications for the development of the Amazon drainage basin," in Amazonia: Landscape and Species Evolution, eds C. Hoorn and F. Wesselingh (Chichester: Wiley-Blackwell), 38-60.

Moran, P. A. (1951). Estimation methods for evolutive processes. J. $R$. Stat. Soc. B Stat. Methodol. 13, 141-146.

Myers, N., Mittermeier, R. A., Mittermeier, C. G., da Fonseca, G. A. B., and Kent, J. (2000). Biodiversity hotspots for conservation priorities. Nature 403, 853-858. doi: 10.1038/35002501

Nürk, N. M., Scheriau, C., and Madriñán, S. (2013). Explosive radiation in high Andean Hypericum - rates of diversification among New World lineages. Front. Genet. 4:175. doi: 10.3389/ fgene.2013.00175
Nylander, J. A. A. (2004). MrModeltest v2. Available online at: https:// github.com/nylander/MrModeltest2

Price, J. P., and Wagner, W. L. (2004) Speciation in Hawaiian angiosperm lineages: cause, consequence and mode. Evolution 58, 2185-2200. doi: 10.1554/03-498

Rambaut, A. (2009). FigTree v1.2.3. Available online at: http://tree.bio. ed.ac.uk/software/figtree

Renner, S. S. (2005). Relaxed molecular clocks for dating historical plant dispersal events. Trends Plant Sci. 10, 550-558. doi: 10.1016/j.tplants. 2005.09.010

Richardson, J. E., Pennington, R. T., Pennington, T. D., and Hollingsworth, P. M. (2001). Rapid diversification of a species-rich genus of neotropical rain forest trees. Science 293, 2242-2245. doi: 10.1126/science. 1061421

Rieseberg, L. H., and Willis, J. H. (2007). Plant speciation. Science 317, 910-914. doi: 10.1126/science. 1137729

Särkinen, T., Pennington, R. T., Lavin, M., Simon, M. F., and Hughes, C. E. (2012). Evolutionary islands in the Andes: persistence and isolation explain high endemism in Andean dry tropical forests. J. Biogeogr. 39, 884-900. doi: 10.1111/j.1365-2699. 2011.02644.x

Smith, S. A., and Donoghue, M. J. (2008). Rates of molecular evolution are linked to life history in flowering plants. Science 322, 86-89. doi: $10.1126 /$ science. 1163197

Valente, L. M., Savolainen, V., and Vargas, P. (2010). Unparalleled rates of species diversification in Europe. Proc. R. Soc. Lond. B Biol. Sci. 277, 1489-1496. doi: 10.1098/rspb.2009. 2163

van der Hammen, T. (1973). The Quaternary of Colombia: introduction to a research project and a series of publications. Palaeogeogr. Palaeoclimatol. Palaeoecol. 14, 1-7. doi: 10.1016/0031-0182(73) 90063-1

van der Hammen, T. (1974). The Pleistocene changes of vegetation and climate in tropical South America. J. Biogeogr. 1, 3-26. doi: 10.2307/3038066

van der Hammen, T., and Cleef, A. M. (1986). "Development of the high Andean Páramo flora and vegetation," in High Altitude Tropical Biogeography, eds F. Vuilleumier and
M. Monasterio (Oxford: Oxford University Press), 153-201.

van der Hammen, T., and Hooghiemstra, H. (2000). Neogene and Quaternary history of vegetation, climate and plant diversity in Amazonia. Quat. Sci. Rev. 19, 725-742. doi: 10.1016/S0277-3791 (99)00024-4

Vargas, O. M., and Madriñán, S. (2012). Preliminary phylogeny of Diplostephium (Asteraceae): speciation rate and character evolution. Lundlellia 15, 1-15.

von Hagen, K. B., and Kadereit, J. W. (2001). The phylogeny of Gentianella (Gentianaceae) and its rapid colonization of the southern hemisphere as revealed by nuclear and chloroplast DNA sequence variation. Org. Divers. Evol. 1, 61-79. doi: 10.1078/1439-609200005

Willis, K. J., Bennett, K. D., and Birks, H. J. B. (2009). Variability in thermal and UV-B energy fluxes through time and their influence on plant diversity and speciation. J. Biogeogr. 36, 1630-1644. doi: 10.1111/j.1365-2699.2009.02102.x

Conflict of Interest Statement: The authors declare that the research was conducted in the absence of any commercial or financial relationships that could be construed as a potential conflict of interest.

Received: 28 May 2013; accepted: 08 September 2013; published online: 09 October 2013.

Citation: Madriñán S, Cortés AJ and Richardson JE (2013) Páramo is the world's fastest evolving and coolest biodiversity hotspot. Front. Genet. 4:192. doi: 10.3389/fgene.2013.00192

This article was submitted to Evolutionary and Population Genetics, a section of the journal Frontiers in Genetics.

Copyright (c) 2013 Madriñán, Cortés and Richardson. This is an open-access article distributed under the terms of the Creative Commons Attribution License (CC BY). The use, distribution or reproduction in other forums is permitted, provided the original author(s) or licensor are credited and that the original publication in this journal is cited, in accordance with accepted academic practice. No use, distribution or reproduction is permitted which does not comply with these terms. 